\title{
THE
}

\section{Tidal Effects on Intermediate Waters: A Case Study in the East/ Japan Sea}

\author{
Ho Jin Lee \\ University of Rhode Island \\ Jae-Hun Park \\ University of Rhode Island \\ Mark Wimbush \\ University of Rhode Island, mwimbush@uri.edu \\ Kyung Tae Jung \\ Chan Joo Jang
}

See next page for additional authors

Follow this and additional works at: https://digitalcommons.uri.edu/gsofacpubs

\section{Citation/Publisher Attribution}

Lee, H. J., Park, J., Wimbush, M., Jung, K. T., Jang, C. J., Cho,...Nam, J. H.(2011). Tidal Effects on Intermediate Waters: A Case Study in the East/Japan Sea. Journal of Physical Oceanography, 41, 234-240. doi: 10.1175/2010JP04510.1 Available at: http://dx.doi.org/10.1175/2010JP04510.1

This Article is brought to you for free and open access by the Graduate School of Oceanography at DigitalCommons@URI. It has been accepted for inclusion in Graduate School of Oceanography Faculty Publications by an authorized administrator of DigitalCommons@URI. For more information, please contact digitalcommons-group@uri.edu. 


\section{Authors}

Ho Jin Lee, Jae-Hun Park, Mark Wimbush, Kyung Tae Jung, Chan Joo Jang, Yang-Ki Cho, Young-Kyo Seo, and Jong Ho Nam

This article is available at DigitalCommons@URI: https://digitalcommons.uri.edu/gsofacpubs/498 


\title{
Tidal Effects on Intermediate Waters: A Case Study in the East/Japan Sea
}

\author{
Ho Jin LeE, * JAE-Hun PARK, AND MARK Wimbush \\ Graduate School of Oceanography, University of Rhode Island, Narragansett, Rhode Island
}

KyUng TAE JUNG AND CHAN JOO JANG

Korea Ocean Research and Development Institute, Ansan, South Korea

\author{
YANG-KI CHO
}

Faculty of Earth Systems and Environmental Sciences, Chonnam National University, Gwangju, South Korea

\author{
YOUNG-KYO SEO AND JONG HO NAM
}

College of Ocean Science and Technology, Korea Maritime University, Busan, South Korea

(Manuscript received 26 May 2010, in final form 16 September 2010)

\begin{abstract}
Although tides are believed to be the most important source for diapycnal mixing in the ocean, few studies have directly simulated open-ocean circulation including tides. Because the East/Japan Sea (EJS) has been considered to be a "miniature ocean," tidal effects on the intermediate water of the EJS are investigated by using an eddy-resolving ocean general circulation model that can take account of $M_{2}$ and $K_{1}$ tides as well as oceanic flows. The simulated temperature and salinity in the intermediate layer are significantly improved by including tides. The improvement results from the combined effect of two internal tides. The $M_{2}$ internal tide, propagating into the interior of the EJS, enhances vertical mixing and brings watermass characteristics closer to those observed. The $K_{1}$ internal tide, trapped along the coast, induces southwestward flow along the Russian coast in the upper layer and thereby enhances the so-called Liman Current, which transports fresh waters with density conducive to the ventilation of intermediate waters in the EJS.
\end{abstract}

\section{Introduction}

Several recent studies have shown a significant impact of tidal mixing on water masses and thereby on oceanic circulation, but most of these studies have incorporated tidal effects through parameterization. For example, enhanced tidal mixing caused by internal tides considerably reduces the bias in temperature $T$ and salinity $S$ when compared with observations (Simmons et al. 2004; Koch-Larrouy et al. 2007) and strengthens ventilation of the North Pacific Ocean intermediate layer (Nakamura

\footnotetext{
* Current affiliation: College of Ocean Science and Technology, Korea Maritime University, Busan, South Korea.

Corresponding author address: Jae-Hun Park, Graduate School of Oceanography, University of Rhode Island, Narragansett, RI 02882-1197.

E-mail: jpark@gso.uri.edu
}

et al. 2006). Indeed, internal tides, which can induce locally intense vertical mixing, are themselves highly influenced by background watermass characteristics (Arbic et al. 2010). Hence multiple-process modeling to include oceanic flows and tides simultaneously is necessary to reproduce the ocean state realistically. Running a global ocean model to resolve internal tides is, however, a challenging problem because of its heavy computational costs. The East/Japan Sea (EJS), a marginal sea of the northwestern Pacific Ocean (Fig. 1), has been considered a miniature ocean, because its circulation system and intermediate-water formation are similar to those of the major oceans yet its area is approximately two orders of magnitude smaller, allowing it to adjust more rapidly. It has therefore been chosen as an ideal basin for high-resolution modeling studies of oceanic processes (Hogan and Hurlburt 2000; Yoon and Kim 2009).

In this study, we investigate tidal effects on intermediate waters of the EJS using an eddy-resolving ocean 


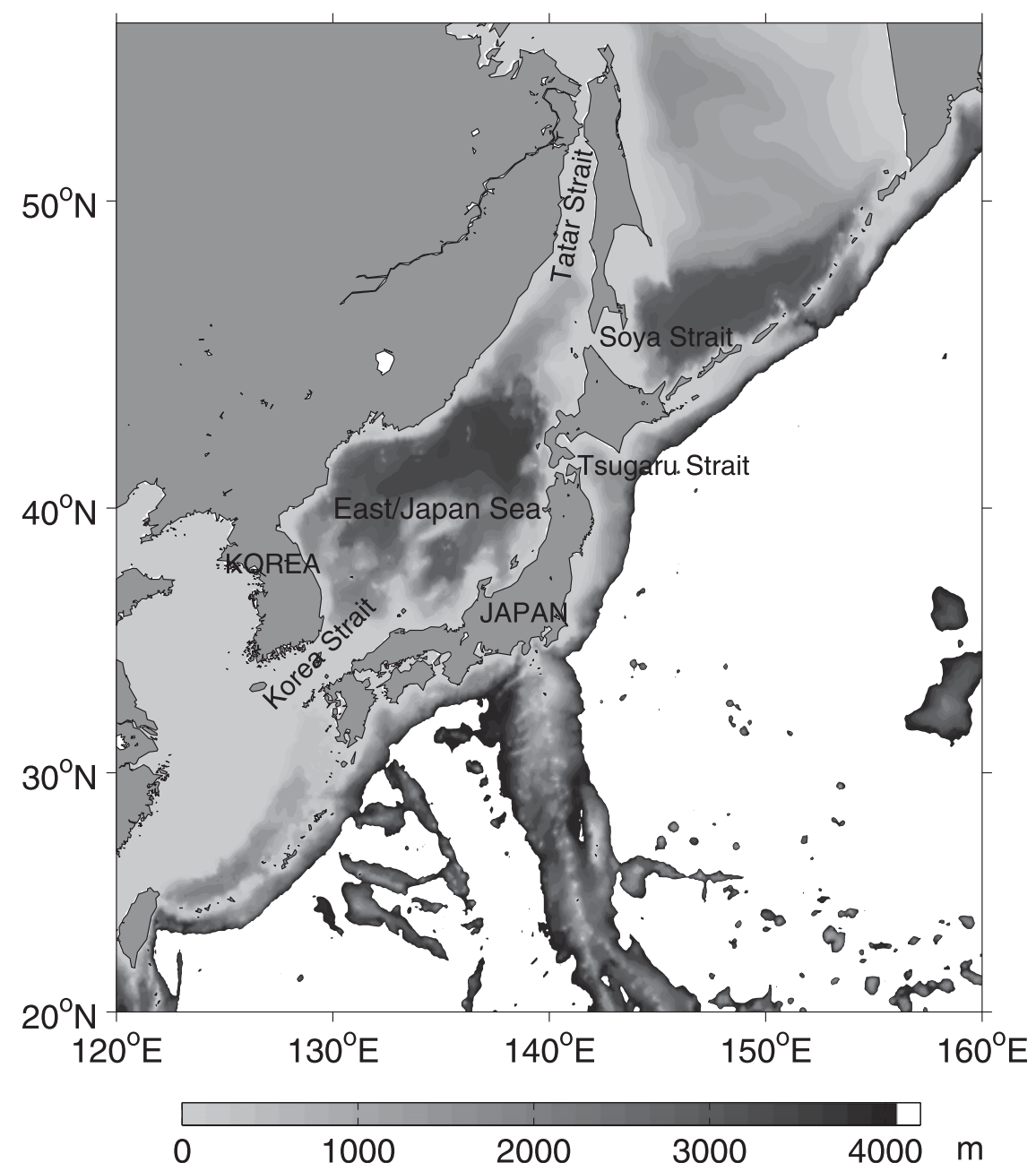

FIG. 1. The East/Japan Sea and its adjacent seas. Bottom topography is contoured every $200 \mathrm{~m}$.

general circulation model (OGCM) that can take account of multiple processes simultaneously. Tides in the EJS are not strong except in four shallow straits that connect it to the northwestern Pacific Ocean, but Park and Watts (2006) show that semidiurnal internal tides are generated near the shelf break of the southern Ulleung Basin and propagate into the interior of the EJS with a high-energy horizontal beam pattern. Furthermore, they show that the propagation patterns and generation energy levels of internal tides are strongly associated with changes in the mesoscale circulation and stratification. We believe that multiple-process modeling of the EJS including tides is a suitable numerical approach for investigating the interaction between tides and oceanic processes.

\section{Model}

The OGCM used in this study is the Research Institute for Applied Mechanics Ocean Model (RIAMOM), which is a three-dimensional, $z$-coordinate, primitive equation ocean model with a free surface (Lee et al. 2003). The model area covers the region $33^{\circ}-52^{\circ} \mathrm{N}, 126.5^{\circ}-142.5^{\circ} \mathrm{E}$ with grid resolution of $1 / 12^{\circ}$ in latitude and longitude. A total of 50 variable vertical levels, with a resolution ranging from $5 \mathrm{~m}$ at the surface to $500 \mathrm{~m}$ at the bottom, are adopted, with a maximum depth of $3800 \mathrm{~m}$. There are 40 vertical levels in the top $700 \mathrm{~m}$ to resolve internal tides well. Biharmonic horizontal mixing is used with coefficients of $3 \times 10^{9} \mathrm{~m}^{4} \mathrm{~s}^{-1}$ for momentum and $6 \times 10^{8} \mathrm{~m}^{4} \mathrm{~s}^{-1}$ for heat and salt. Vertical mixing coefficients are calculated with the Noh et al. (2002) vertical mixing scheme based on a second-order turbulence closure.

Monthly-mean European Centre for Medium-Range Weather Forecasts forecast data with $0.5^{\circ}$ resolution during 1999-2008 are used to calculate sea surface fluxes as well as wind stress at the sea surface. Surface salinity relaxation with a time scale of 10 days is added to correct 

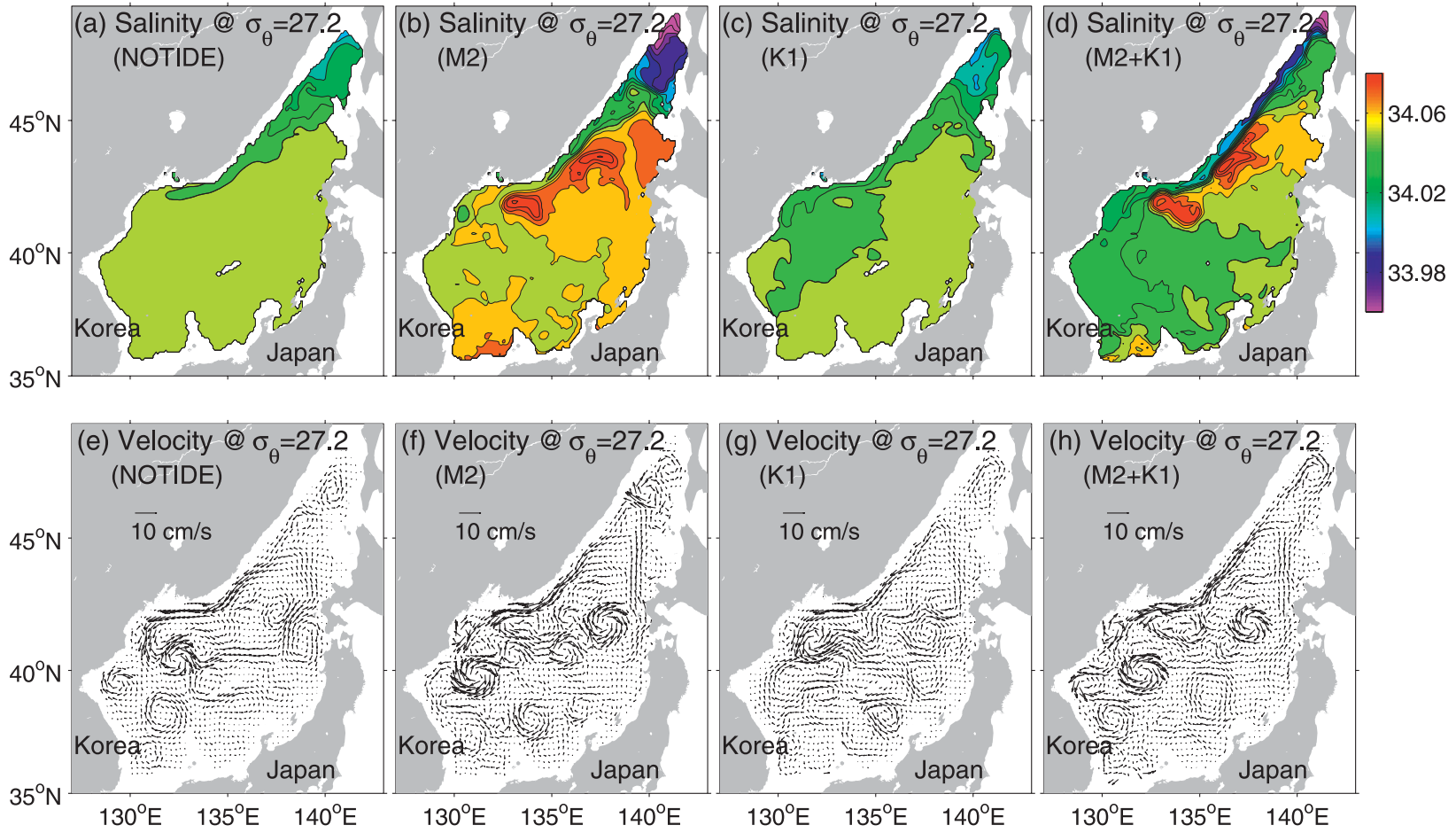

FIG. 2. (a)-(d) Salinity distribution on the $\sigma_{\theta}=27.2 \mathrm{~kg} \mathrm{~m}^{-3}$ isopycnal surface for different tidal combinations as labeled. Contour interval is 0.01 , and thick contours indicate $S=34.05$. (e)-(h) Corresponding flow fields on the same density surface.

the freshwater flux, whereas heat fluxes are computed with a bulk formula without the relaxation of sea surface temperature. Temperature and salinity imposed at inflow open boundaries and salinity relaxed at the sea surface are from the $1 / 4^{\circ}$ Generalized Digital Environmental Model (GDEM) "climatology" (Teague et al. 1990; Chu et al. 2002) (available online at http://www. usgodae.org/). The initial ocean state is set to have uniform temperature and salinity profiles produced using domain-averaged August data from the Japan Ocean Data Center.

For the normal component of depth-mean flow along the open boundaries, a Flather-type radiation condition is adopted:

$$
\bar{u}=\bar{u}_{m}+\bar{u}_{T}+\frac{\sqrt{g h}}{h}\left(\eta-\eta_{m}-\eta_{T}\right)
$$

where $\bar{u}$ and $\eta$ are velocity and sea surface elevation computed at the open boundary grid points, $\bar{u}_{T}$ and $\eta_{T}$ are the prescribed tidal currents and elevation, and $\bar{u}_{m}$ and $\eta_{m}$ are the prescribed oceanic currents and elevation. Both $\bar{u}_{T}$ and $\eta_{T}$ are given as a sinusoidal form using satellite-altimetry-assimilated tidal model outputs (Lee et al. 2001). This model agrees well with results derived from deep-sea pressure measurements at 23 sites in the southern EJS [cf. Fig. 5 in Lee et al. (2001) with Fig. 3 in Park et al. (2006)]. The semidiurnal tidal currents are stronger than the diurnal ones in the Korea and Tatar Straits, and the diurnal tidal currents are stronger in the Tsugaru and Soya Straits. Here we include $M_{2}$ and $K_{1}$ tides, which represent respectively the major semidiurnal and diurnal tidal constituents in the EJS.

A series of preliminary model runs was carried out to determine $\bar{u}_{m}$ and $\eta_{m}$ based on the monthly-mean volume transport of the Tsushima Warm Current (TWC) from 1976 to 2005 (Nishimura et al. 2008). We started the calculation with zero values of $\bar{u}_{m}$ (except for prescribing the TWC at the inflow boundary) and $\eta_{m}$ and then replaced $\bar{u}_{m}$ and $\eta_{m}$ at all open boundaries regularly (every 6 months) with values computed at the nearest interior grid. The procedure was repeated until optimum values satisfying mass balance between inflow and outflow were acquired. For the inflow boundary (Korea Strait), the volume transport had a range of $1.84-3.0 \mathrm{~Sv}$ ( $1 \mathrm{~Sv} \equiv$ $10^{6} \mathrm{~m}^{3} \mathrm{~s}^{-1}$ ) with an annual mean of $2.56 \mathrm{~Sv}$. The estimated outflow volume transport had a range of 0.94-1.84 Sv with an annual mean of $1.46 \mathrm{~Sv}$ at the Tsugaru Strait and 0.91-1.24 Sv with an annual mean of $1.1 \mathrm{~Sv}$ at the Soya Strait. These values are comparable to those obtained from various observational studies shown in a review paper by $\mathrm{Na}$ et al. (2009). 
(a) T (NOTIDE)

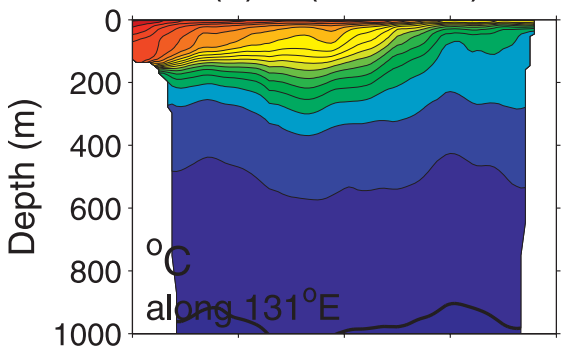

(d) S (NOTIDE)

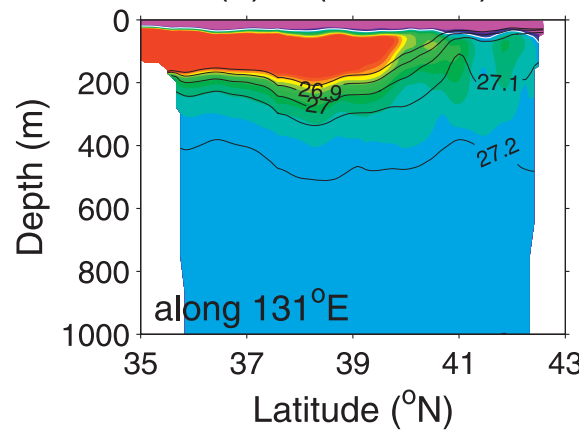

(b) $\mathrm{T}(\mathrm{M} 2+\mathrm{K} 1)$

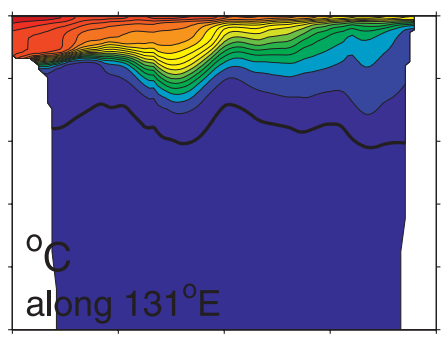

(e) $\mathrm{S}(\mathrm{M} 2+\mathrm{K} 1)$

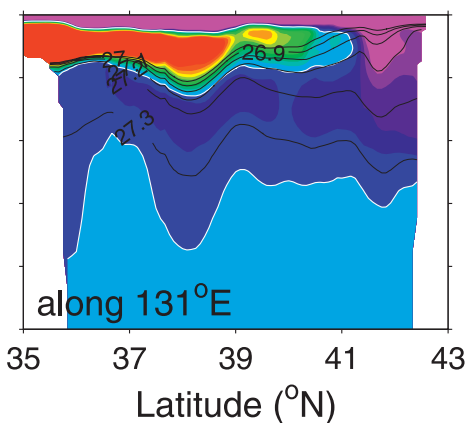

(c) T (GDEM)

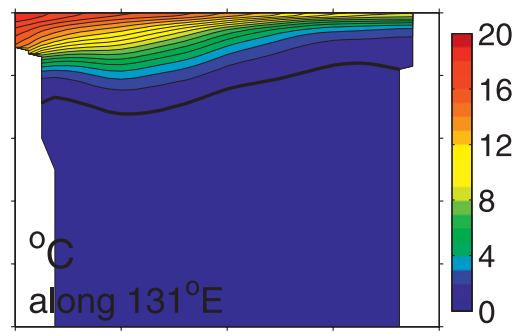

(f) $\mathrm{S}$ (GDEM)

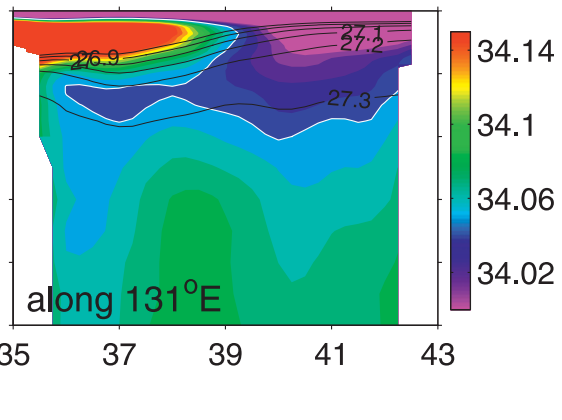

FIG. 3. The meridional section of potential temperature along $131^{\circ} \mathrm{E}$ for (a) NOTIDE, (b) M2+K1, and (c) the GDEM climatology. Contour interval is $1.0^{\circ} \mathrm{C}$, and thick contours indicate $1.0^{\circ} \mathrm{C}$. (d),(e),(f) Corresponding salinities at the same section. Contour interval is 0.01 , and white contours indicate $S=34.05$. The solid contours indicate isopycnal layers from $\sigma_{\theta}=26.8 \mathrm{~kg} \mathrm{~m}^{-3}$ to $\sigma_{\theta}=27.3 \mathrm{~kg} \mathrm{~m}$ with an interval of $0.1 \mathrm{~kg} \mathrm{~m}^{-3}$.

\section{Results and discussion}

Four different cases of numerical simulations are conducted with 1) no tidal forcing (NOTIDE), 2) $M_{2}$ tide only (M2), 3) $K_{1}$ tide only (K1), and 4) both $M_{2}$ and $K_{1}$ tides $(\mathrm{M} 2+\mathrm{K} 1)$. Time integration is carried out for $50 \mathrm{yr}$, and yearly averaged values for the final year are used for the analysis.

Figure 2 shows horizontal distributions of salinity and velocity fields on the $\sigma_{\theta}=27.2 \mathrm{~kg} \mathrm{~m}^{-3}$ surface, which is regarded as the middle of the East Sea Intermediate Water (ESIW; $S \leq 34.06$ ) as well as the High Salinity Intermediate Water (HSIW; $S \geq 34.07$ ) (Kim and Kim 1999). In comparison with hydrographic observations [e.g., Fig. 7 in Kim and Kim (1999) and Fig. 34 in Talley et al. (2004)], the M2+K1 case reproduces the most realistic distribution of ESIW as well as HSIW: the eastward extension of the ESIW along $40^{\circ} \mathrm{N}$ and the presence of HSIW. It is notable that fresher waters exist north of $45^{\circ} \mathrm{N}$ in the $\mathrm{M} 2$ and $\mathrm{M} 2+\mathrm{K} 1$ cases (Figs. 2a-d).

The fresh waters north of $45^{\circ} \mathrm{N}$ are believed to be transported by southwestward flows parallel with the Russian coast and to penetrate the intermediate layer of the EJS (Figs. 2e-h). Though the southwestward flow, the so-called Liman Current, exists in all cases, the $\mathrm{M} 2+\mathrm{K} 1$ case shows the most persistent flow from the northern end of the EJS. We note that the M2 case shows northeastward flows around $47^{\circ} \mathrm{N}$, which block the path of the freshwater. The differences in the flow fields north of $45^{\circ} \mathrm{N}$, especially along the Russian coast, explain why the penetration of the ESIW into the intermediate layer is more clearly reproduced in the $\mathrm{M} 2+\mathrm{K} 1$ case.

In comparison with the GDEM, the $\mathrm{M} 2+\mathrm{K} 1$ case reproduces well the main ESIW features on the meridional section along $131^{\circ} \mathrm{E}$ : the depth of the ESIW and its southward penetration following isopycnal surfaces between $\sigma_{\theta}=27.1$ and $\sigma_{\theta}=27.3 \mathrm{~kg} \mathrm{~m}^{-3}$ (Fig. 3). With the exception that the salinity is slightly lower than that observed by about 0.01 , the simulated features are similar to those observed (Fig. 7 in Talley et al. 2004). The thermocline south of $37^{\circ} \mathrm{N}$ is enhanced in $\mathrm{M} 2+\mathrm{K} 1$ than in NOTIDE, probably because of the high-temperature surface water supplied by the TWC as well as the cooling of intermediate layers.

The vertical structure of the temperature field (and hence density field) shows an improvement when the $M_{2}$ and $K_{1}$ tides are included, even though the temperature is about $1^{\circ} \mathrm{C}$ higher than the GDEM north of $40^{\circ} \mathrm{N}$ at depths between 200 and $400 \mathrm{~m}$. Intermediatelayer temperature improvement is also obtained in the M2 case; nevertheless, penetration of ESIW from the sea surface is not represented in the M2 case (not shown). 


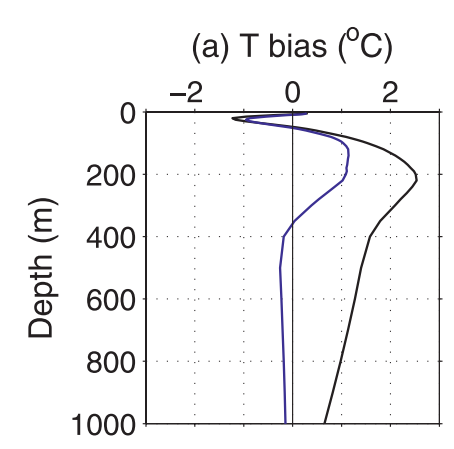

(d) notide

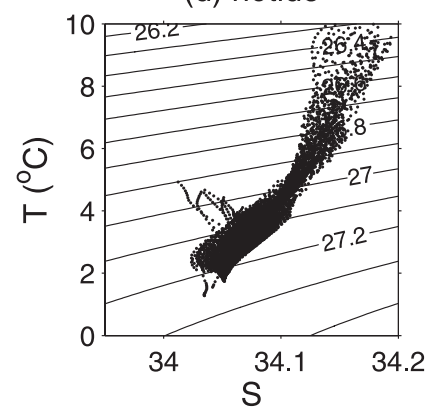

(b) $\mathrm{S}$ bias

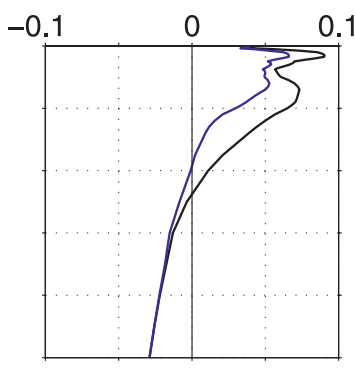

(e) $\mathrm{M} 2+\mathrm{K} 1$

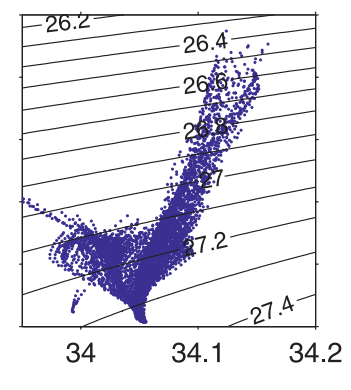

(c) Vertical diffusivity $\left(\mathrm{cm}^{2} / \mathrm{s}\right)$

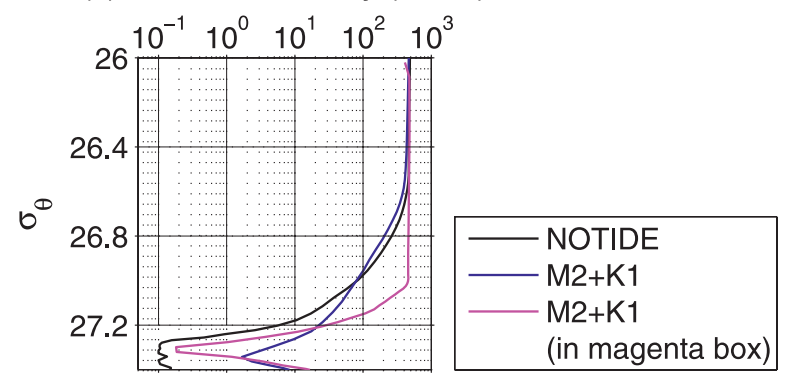

(g) T-S locations

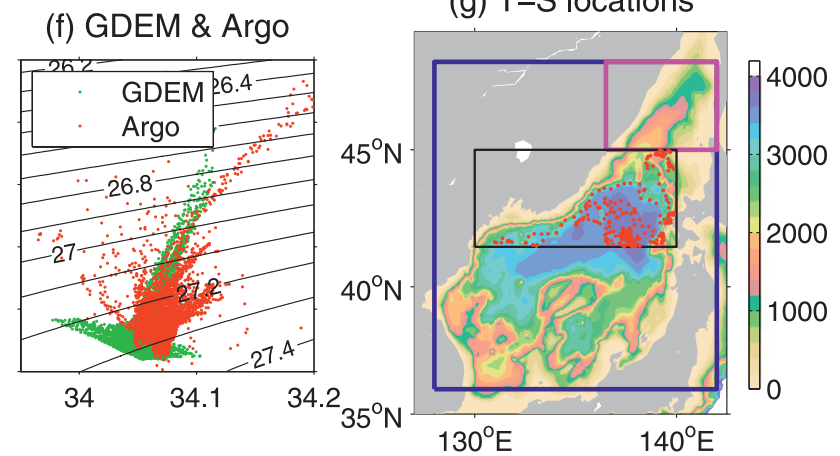

FIG. 4. (a) Temperature and (b) salinity biases (i.e., departures from GDEM), and (c) vertical diffusivity averaged inside the blue box in (g). Black curves are for the NOTIDE case, and blue curves are for the M2+K1 case. The magenta curve in (c) shows vertical diffusivity averaged inside the region noted by the magenta box in (g). The $T-S$ diagrams are shown for (d) the NOTIDE case, (e) the M2+K1 case, and (f) GDEM (green dots) and Argo (red dots) data at depths between 100 and $400 \mathrm{~m}$ in the region denoted by the black box in (g). (g) Locations used in (a)-(f): colored contours indicate the bottom topography, and red dots indicate the locations of Argo observations.

The domain-averaged temperature and salinity biases decrease by factors of about $2-10$ depending on depth when the $M_{2}$ and $K_{1}$ tides are included in the simulation (Figs. 4a,b). The temperature biases are reduced by about $1.5^{\circ} \mathrm{C}$ at depths between 100 and $600 \mathrm{~m}$ and by about $1^{\circ} \mathrm{C}$ at depths that are deeper than $600 \mathrm{~m}$. The salinity biases are reduced by about 0.03 at depths between the surface and $400 \mathrm{~m}$. The salinity bias improvement diminishes at depths of greater than $400 \mathrm{~m}$. Note that the scarcity of data at depths deeper than $500 \mathrm{~m}$ used to build the GDEM is most likely the main reason of this degradation (Chu et al. 2002).

To understand the effect of tidal mixing on water masses, we have calculated a horizontally averaged vertical diffusivity on isopycnal surfaces (Fig. 4c). The difference in vertical diffusivity between the NOTIDE and $\mathrm{M} 2+\mathrm{K} 1$ cases is notable for water masses that are denser than $\sigma_{\theta}=27.0 \mathrm{~kg} \mathrm{~m}^{-3}$. We especially note that a stronger enhancement by tides exists in the region north of $45^{\circ} \mathrm{N}$ (magenta box in Fig. $4 \mathrm{~g}$ ). The enhanced vertical mixing affects water masses with the density range of $26.8 \mathrm{~kg} \mathrm{~m}^{-3}<\sigma_{\theta}<27.2 \mathrm{~kg} \mathrm{~m}^{-3}$, which is nearly the same as that of the ESIW: $26.9 \mathrm{~kg} \mathrm{~m}^{-3}<\sigma_{\theta}<$ $27.3 \mathrm{~kg} \mathrm{~m}^{-3}$ (Kim and Kim 1999).
Water masses in the northern EJS become denser and fresher because of the enhanced vertical mixing north of $45^{\circ} \mathrm{N}$ (Figs. $4 \mathrm{~d}, \mathrm{e}$ ). It is worth noting that there are few water masses that have $\sigma_{\theta}$ greater than $27.2 \mathrm{~kg} \mathrm{~m}^{-3}$ in the NOTIDE case as contrasted with the $\mathrm{M} 2+\mathrm{K} 1$ case. The M2+K1 case (Fig. 4e) strongly resembles a composite $T-S$ diagram of GDEM and Argo observations (Fig. 4f). The denser and fresher water would be transported eventually into the entire intermediate layer of the EJS. Nakamura et al. (2006) have suggested that tidally enhanced mixing at the Kuril Strait strengthens ventilation of the intermediate layer and thereby makes the North Pacific Intermediate Water fresher and denser. Our results suggest that tidal mixing north of $45^{\circ} \mathrm{N}$ plays a similar role in ventilating the intermediate layer in the EJS.

We also examined why the southwestward flows along the Russian coast north of $45^{\circ} \mathrm{N}$ are more persistent in the $\mathrm{M} 2+\mathrm{K} 1$ case than in the $\mathrm{M} 2$ case, employing internal tide simulations without any other forcings. Figure 5 shows that the $\sigma_{\theta}=26.0 \mathrm{~kg} \mathrm{~m}^{-3}$ surface becomes inclined downward toward the Russian coast with a resulting southwestward flow along the coast when the $K_{1}$ tide is included. This southwestward flow still exists when 

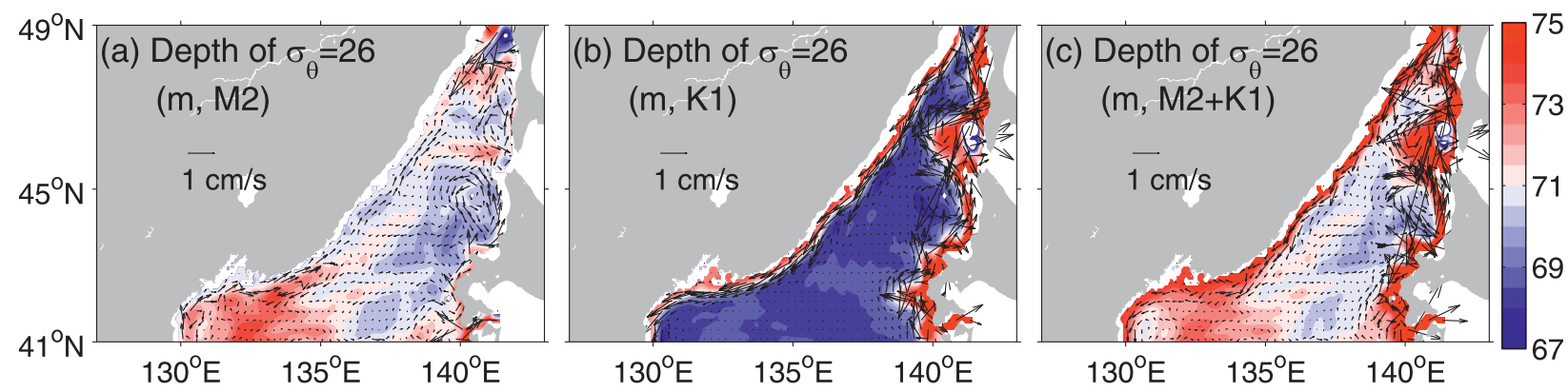

FIG. 5. The depth of the $\sigma_{\theta}=26.0 \mathrm{~kg} \mathrm{~m}^{-3}$ isopycnal surface and flow fields at that isopycnal surface after 1 yr of integration with no forcings other than (a) $M_{2}$ tide, (b) $K_{1}$ tide, and (c) $M_{2}$ and $K_{1}$ tides. The isopycnal surface $\sigma_{\theta}=26.0 \mathrm{~kg} \mathrm{~m}^{-3}$ is initially located at a depth of about $70 \mathrm{~m}$, which corresponds to the top of the thermocline.

both the $M_{2}$ and $K_{1}$ tides are included, although weak northeastward flow is generated along the Russian coast in the case of $M_{2}$ tide only.

Whereas the $M_{2}$ internal tide can propagate into the interior of the EJS, the $K_{1}$ tide generates a coastally trapped internal Kelvin wave because its period is longer than the inertial period in the EJS (Park and Watts 2006). Støylen and Weber (2010) show that a coastally trapped internal Kelvin wave induces a small mass flux in the offshore direction and consequently facilitates a geostrophically balanced boundary current in enclosed basins. The offshore mass flux is caused by a small damping factor $\alpha$ for internal tides. By assuming a $K_{1}$ internal tide with wavelength $\lambda$ of $100 \mathrm{~km}$, upper-layer thickness of $100 \mathrm{~m}$, and vertical viscosity of $3 \mathrm{~cm}^{2} \mathrm{~s}^{-1}$, the damping distance $1 / \alpha$ is calculated to be about $555 \mathrm{~km}$. These values seem to meet the assumption $L_{d} \ll \lambda \ll 1 / \alpha$ for the theory suggested by Støylen and Weber (2010), since the internal deformation radius $L_{d}$ is of order $20 \mathrm{~km}$ in the EJS. We presume the $K_{1}$ tidal current flowing through the Soya Strait results in this upper-layer southwestward flow.

\section{Conclusions}

Tidal effects on the intermediate water of the EJS have been investigated using an eddy-resolving OGCM that resolves multiple processes simultaneously. The intermediate layer of the EJS appears to be highly rectified by tides. The $M_{2}$ internal tide, through its associated vertical shear and resulting turbulence kinetic energy, is believed to be a possible source for the enhancement of vertical mixing. In particular, the enhanced mixing makes water masses denser and fresher in the northern EJS and brings the model output closer to the observed features.

The domain-averaged temperature and salinity biases are improved considerably, as the modified water masses in the northern EJS are transported into the entire intermediate layer of the EJS. In addition to tidal mixing, the coastal trapped $K_{1}$ internal tide enhances the winddriven southwestward flow along the coastal boundary (i.e., the Liman Current) in the upper layer through an internal-wave-induced setup demonstrated by Støylen and Weber (2010). This enhancement of flow plays an important role in the transport of fresh waters along the Russian coast. Our study indicates that direct inclusion of tide-induced processes significantly improves OGCM results in the EJS.

We anticipate a seasonal variation in the strength of the tide-induced currents because they depend strongly on the stratification. Future studies will address the seasonal variation of tidal effects in the EJS and will be extended to examine similarly tidal effects on the North Pacific Ocean circulation. With expected advances in available computational power over the next decade, it will become increasingly feasible to include tides in models of major oceans or even those of the global ocean; the results from our EJS study suggest that this will result in significant improvement in the capability of these models to simulate observed ocean conditions and circulations.

Acknowledgments. We thank two anonymous reviewers for their helpful comments and suggestions. This study was supported by the National Agenda Project funded by KRCF and KORDI (PE98501). Also the authors are grateful for financial support from the Industrial Strategic Technology Development Program (10033640) of the Ministry of Knowledge and Economy of Korea.

\section{REFERENCES}

Arbic, B. K., A. J. Wallcraft, and E. J. Metzger, 2010: Concurrent simulation of the eddying general circulation and tides in a global ocean model. Ocean Modell., 32, 175-187. 
Chu, P. C., W. Guihua, and Y. Chen, 2002: Japan Sea thermohaline structure and circulation. Part III: Autocorrelation functions. J. Phys. Oceanogr., 32, 3596-3615.

Hogan, P. J., and H. E. Hurlburt, 2000: Impact of upper-oceantopographical coupling and isopycnal outcropping in Japan/ East Sea models with $1 / 8^{\circ}$ to $1 / 64^{\circ}$ resolution. J. Phys. Oceanogr., 30, 2535-2561.

Kim, Y. G., and K. Kim, 1999: Intermediate waters in the East/ Japan Sea. J. Oceanogr., 55, 123-132.

Koch-Larrouy, A., G. Madec, P. Bouruet-Aubertot, T. Gerkema, L. Bessières, and R. Molcard, 2007: On the transformation of Pacific Water into Indonesian Throughflow Water by internal tide mixing. Geophys. Res. Lett., 34, L04604, doi:10.1029/ 2006GL028405.

Lee, H. J., J. H. Yoon, H. Kawamura, and H. W. Kang, 2003: Comparison of RIAMOM and MOM in modeling the East Sea/Japan Sea circulation. Ocean Polar Res., 25, 287-302.

Lee, J. C., C. S. Kim, K. Matsumoto, and M. Ooe, 2001: Computation of tides in the northeast Asian Sea by blending the TOPEX/Poseidon altimeter data (in Korean with English abstract). The Sea J. Korean Soc. Oceanogr., 6, 1-12.

Na, H., Y. Isoda, K. Kim, Y. H. Kim, and S. J. Lyu, 2009: Recent observations in the straits of the East/Japan Sea: A review of hydrography, currents and volume transports. J. Mar. Syst., 78, 200-205.

Nakamura, T., T. Toyoda, Y. Ishikawa, and T. Awaji, 2006: Effects of tidal mixing at the Kuril Straits on North Pacific ventilation: Adjustment of the intermediate layer revealed from numerical experiments. J. Geophys. Res., 111, C04003, doi:10.1029/ 2005JC003142.
Nishimura, K., N. Hirose, and K. Fukudome, 2008: Long-term estimation of volume transport through the Tsushima Straits (in Japanese with English abstract). Rep. Res. Inst. Appl. Mech., 135, 113-118.

Noh, Y., C. J. Jang, T. Yamagata, P. C. Chu, and C. H. Kim, 2002: Simulation of more realistic upper-ocean processes from an OGCM with a new ocean mixed layer model. J. Phys. Oceanogr., 32, 1284-1307.

Park, J.-H., and D. R. Watts, 2006: Internal tides in the southwestern Japan/East Sea. J. Phys. Oceanogr., 36, 22-34.

, M. Wimbush, J. W. Book, K. L. Tracey, and Y. Xu, 2006: Rapid variability in the Japan/East Sea: Basin oscillation, internal tides, and near-inertial oscillations. Oceanography, 19, 76-85.

Simmons, H. L., S. R. Jayne, L. C. S. Laurent, and A. J. Weaver, 2004: Tidally driven mixing in a numerical model of the ocean general circulation. Ocean Modell., 6, 245-263.

Støylen, E., and J. E. H. Weber, 2010: Mass transport induced by internal Kelvin waves beneath shore-fast ice. J. Geophys. Res., 115, C03022, doi:10.1029/2009JC005298.

Talley, L. D., P. Tishchenko, V. Luchin, A. Nedashkovskiy, S. Sagalaev, D. J. Kang, M. Warner, and D. H. Min, 2004: Atlas of Japan (East) Sea hydrographic properties in summer, 1999. Prog. Oceanogr., 61, 277-348.

Teague, W. J., M. J. Carron, and P. J. Hogan, 1990: A comparison between the Generalized Digital Environmental Model and Levitus climatologies. J. Geophys. Res., 95, 7167-7183.

Yoon, J. H., and Y. J. Kim, 2009: Review on the seasonal variation of the surface circulation in the Japan/East Sea. J. Mar. Syst., 78, 226-236. 